\title{
Wage Convergence across European Regions : Do International Borders Matter?
}

\author{
Amber Naz \\ Sultan Qaboos University, Oman \\ Nisar Ahmad \\ Sultan Qaboos University, Oman \\ Amjad Naveed \\ University of Southern Denmark, Denmark
}

\begin{abstract}
This study focuses on wage convergence among the member states of the European Union by addressing three important questions. First, is there average wage convergence in European Union regions? Second, if there is wage convergence, are regional wage levels converging to a single, steady state level (unconditional convergence) or to their own steady state level (conditional convergence)? Third, do international borders matter for average wage convergence? By using a panel data set covering 203 Nomenclature of Territorial Units for Statistics-2 level regions from 1996 to 2006, the present study finds wage convergence for internal regions (regions within the same country) but no evidence of convergence for border regions (neighboring regions across international borders).

\footnotetext{
* Corresponding Author: Amjad Naveed; Department of Business and Economics, University of Southern Denmark, Alsion 2, 6400 Sønderborg, Denmark, Tel: +4565501247, Fax:+4565501779, E-Mail: amjadn@sam.sdu.dk, amjadnaveed9@yahoo.com Co-authors: Amber Naz; Department of Economics and Finance, Sultan Qaboos University, P.O.Box, PC 123, Al-Khod, Oman, Tel: +96890123893, Fax:+96824144043, E-Mail: ammi3212@gmail.com.

Nisar Ahmad; Department of Economics and Finance, Sultan Qaboos University, P.O.Box, PC 123, Al-Khod, Oman, Tel: +96824142098, Fax: +9682414 4043, E-Mail: nisar@squ.edu.om.
} 
These results imply that wage convergence is somehow restricted by international borders. These results are robust with both parametric and non-parametric approaches of testing convergence.

JEL Classifications: C01, C12, C23, F15, J31

Keywords: Average Wage, Convergence, Panel Unit Root Test, Factor Mobility, Border Regions

\section{Introduction}

Regional convergence is a principal focus of European Union (EU) policies. To achieve this objective, the European Single Market policy was implemented in 1993 for EU regions, targeting the free movement of people, goods, and services. The free market literally provides a channel for establishing free trade and unrestricted international mobility between European countries. Researchers and scholars agree that free trade and mobility are two mandatory conditions for factor price equalization or, in a more dynamic sense, factor price convergence. The literature on international trade suggests that lowering trade barriers has a positive impact on both cross-border factor and production markets. Ohlin (1933, 31 32), in his seminal paper, summarized the factor price equalization theorem as: "Free mobility of commodities in international trade can serve as a partial substitute for factor mobility and will lead to a partial equalization of relative (and absolute) factor prices."

The mechanism through which this equalization works is the reallocation of resources in both the production and labor markets. This reallocation of resources, in turn, not only affects the demand and supply of goods and services but also influences the labor market through a change in demand and supply of labor. These changes, in turn, change the return to the factors or their prices. 'In the Hecksher-Ohlin trade theorem, the equalization of factor prices is established by trading those goods in which the countries are specialized or have comparative advantage (see Krugman et al. 2011).

International trade theory under the neoclassical framework suggests that labor moves

${ }^{1}$ For a more comprehensive discussion on the factor price equalization theorem, see Samuelson (1948). 
from one region to another because of regional differences in wages and unemployment. Labor moves from low-wage regions to high-wage regions to improve welfare. This movement causes a reallocation of resources and reduction in the factor price disparities among regions. A recent study by Naveed et al. (2016) showed the differential effect of labor mobility on local employment in various types of regions. Furthermore, a reduction in wage difference is a signal for convergence of wages or is, in turn, an indicator of labor market convergence. Thus, free mobility is another auxiliary argument in exploring the convergence phenomenon vis-à-vis wages. Theoretically, there exists a negative association between wage disparities and labor mobility. Thus, higher mobility implies the reduction in wage differences between regions or countries. Accordingly, within the argument of free mobility of production factors, one can expect factor price convergence in labor markets of distinct regions. Thus, free trade and mobility are two arguments that encourage convergence in both factor and commodity markets. Wage convergence can be viewed through the lens of mass migrations starting from the end of the 19th century and continuing until the start of the First World War. People migrated for multifarious social and economic reasons, such as higher wages or better economic welfare. Taylor and Williamson (1997) explored the differences in real wages for the 1870 1913 period and found a prominent decline in the real wages of destination countries and considerable increase in the real wages of the origin countries.

Since 1993, high-waged European states have experienced increasing flows of immigrants from low-waged European states. For instance, countries such as England, Germany, Denmark, and France have witnessed high flows of immigrants from lowwage European countries such as Poland, Romania, and the Czech Republic. It was expected that migration from Eastern Europe to Western Europe would amount to 3\% of the population of the Eastern European countries in 1999. ${ }^{2}$ The 1990 1999 period was known for the development of two main ideas by the EU: a borderless Europe and a single market. These two measures, which are intended to attain economic convergence across the EU, push the price equalization discussion to the forefront because they imply free trade and mobility of labor. Labor, goods, and services can, in principle, move without obstruction after the implementation of convergence policy measures. These circumstances advance many research questions vis-à-vis price equalization that need to be answered. For instance, does the empirical evidence suggest that greater geographical mobility and partially free trade contribute to wage equalization (convergence) in reality?

\footnotetext{
${ }^{2}$ For more details, see Bauer and Klaus (1999).
} 
Do borders really become less important or are they still serving as an impediment to integration and convergence? Does this convergence in wages support the argument for factor price convergence? Does the wage convergence bring European commodity and labor markets closer to each other? Does free trade cause dynamic reductions in the differences of commodity and factor prices or convergence in the prices? A recent study by Naveed and Ahmad (2016a) also analyzed the effect of international borders on the spillover of knowledge and technology in EU regions and indicated that knowledge spillovers largely occur regionally, within countries, and spillovers across international borders are not significant.

Although the labor force today is more mobile and fewer trade impediments exist compared with the situation in 1993, substantive differences in wages and commodity prices still prevail. Some European countries still exhibit relatively high wages, such as Denmark, France, and Spain; others are associated with relatively low wages, such as Germany. ${ }^{3}$ Thus, there is a need to explore the reality of the situation, especially in the labor markets of European countries. In other words, why are the disparities between lower- and higher-wage member states not declining over time, as indicated by price equalization theory? Factor price convergence, which is an outcome of this theory, is not seen among EU member states. Therein lies the motivation for this study. European border regions are appropriate laboratories to analyze the impact of free trade and mobility on wage convergence because factor markets are distinct on both sides of the border. Thus, the factor convergence hypothesis can be tested under the two mandatory conditions of factor mobility and free trade. Labor can physically commute across borders on a daily basis in certain cases wherein the proximities of destination and origin make this feasible. Borders are often conceived as hurdles or impediments that militate against economically optimal outcomes. In this study, we explore whether eliminating physical borders really matters for factor price convergence.

Specifically, we address three important questions here. First, is there average wage convergence in EU regions? Second, if there is wage convergence, are regional wage levels converging to a single, steady state level (unconditional convergence) or to their own steady state level (conditional convergence)? Finally, do international borders matter for wage convergence? For estimation purposes, we employ a unique data set for 203 Nomenclature of Territorial Units for Statistics (NUTS)-2 level EU regions over the 1996 2006 period. The regions are divided into two categories: internal regions (defined

European Price Statistics An overview, (2008) available on: http://epp.eurostat.ec.europa.eu/cache/ITY_OFFPUB/KS-70-07-038/ EN/KS-70-07-038-EN.PDF. 
as neighboring regions within a country) and border regions (defined as neighboring regions across international borders). We use panel unit root procedures to test the convergence hypothesis. The results of this study show that wage convergence exists for all internal regions. However, with regard to the effect of international borders, the results are not robust across different specifications. This implies that ameliorating legal, physical, and administrative barriers may not be enough to integrate the labor markets with respect to returns to factors of production. Mechanisms that influence factor market integration could be language barriers, cultural differences, local rules and regulations, legal issues, or property rights. A similar argument was discussed by Naveed and Ahmad (2016a) with respect to the negative effects of borders on knowledge and technology transfers among EU border regions. Therefore, for the integration of wages in border regions, these barriers need to be reduced. The empirical literature on regional wage convergence for European regions is relatively limited, especially with reference to border regions; therefore, the present study offers a unique contribution with respect to furthering knowledge and understanding of wage convergence. Specifically, the contribution of this study lies in two domains of literature. First, it contributes to the convergence literature for European regions, and second, it will also contribute to the literature on integration among EU border regions.

The rest of the study is structured as follows: Section II offers a short review of relevant theory and literature; Section III presents detailed descriptions of concepts and methods on convergence; Section IV delineates panel unit root tests, used to the quantify the nature and magnitude of convergence; Section V provides details about data and their sources; Section VI reports results; and, finally, Section VII concludes the study.

\section{Theory and Literature}

The concept of wage convergence, which is derived from factor price equalization, can be explored via the literature on international trade and labor economics. In the international trade literature, factor price equalization can be discussed as an outcome of the Hecksher-Ohlin trade model, which is designed for two economies, two products, and two production factors. It is a trade model that shows patterns of trading for those goods that are produced by the factor that is abundant in a certain country. Factor price 
equalization has certain restrictions such as identical technologies and sufficiently similar factor supply ratio. Moreover, it also demands an absolute equality of prices of commodities and factors, whereas the concept of factor price convergence is more flexible in the sense that it does not require the absolute equality of factor and commodity prices among the countries under free trade. Leamer $(1995,7)$ attempted to define factor price convergence as a process that occurs "When two countries eliminate their mutual trade barriers, product price equalization eliminates factor price differences."

Thus, under the Hecksher-Ohlin trade model, factor price convergence induces convergence through commodity price convergence and there is no mobility of factors of production. Through the reduction of barriers in the form of borders between the countries, the local labor and commodity markets become the global markets and a reallocation of resources takes place in product and factor markets. The factor prices are affected by the changes in the labor supply and demand induced by the mobile factors across borders. The changes in the product market are directed by the reallocation of resources. The derived demand for the commodities and factors with the free trade notion induce convergence in commodity prices and factor prices across regions or countries. Factor price convergence can be expected even if the mobility of factors among the countries is disregarded as it helps reducing disparities in demand relative to factor supply, which subsequently helps in curtailing the differences in factors returns.

For wage convergence, the empirical evidence is equivocal. For instance, Mora et al. (2005) analyzed wage and productivity convergence by applying different methods for convergence in European countries for the 1981 2001 period. Their study is based on three different methods of convergence: $\beta$ convergence, $\sigma$ convergence, and the unit root method. They found support for the $\beta$ convergence of wages but no evidence for $\sigma$ convergence or with respect to time series unit root tests for convergence. Their results support wage convergence but not productivity convergence. Further, they also found different patterns for real and nominal wages and suggested that the European single currency does not substantively support the process of wage equalization. Webber and White (2003) and Webber (2001) also tested labor cost convergence for $58 \mathrm{EU}$ regions across four major countries - Germany, Spain, the Netherlands, and Italyover the 1980 1994 period. Their results suggest progressive wage convergence based on application of the concordance method, a non-parametric tool to capture wage he convergence. Both these studies support wage convergence during the sample period.

Revenga (1997) investigated the impact of trade liberalization on wages in Mexican manufacturing and found that trade liberalization influences wages. Jung and Doroodian 
(2000) also found strong evidence of manufacturing labor cost convergence between countries in Western Europe compared with those in North America over a 30-year time frame. They also presented an interesting argument that factor price convergence is actually the dynamic version of factor price equalization. Taylor and Williamson (1997) provided positive evidence for factor price convergence among Organisation for Economic Co-operation and Development (OECD) countries for the 1870 1913 period. Their results suggest that the wage gap between new and old worlds reduced $23 \%$ between 1870 and 1910. This real wage convergence is mostly based on migration from the old world to the new world. Further, their results also suggest, as a corollary, that this real wage gap increases in the absence of migration.

Erickson and Kuruvilla (1994) provided negative evidence for labor cost convergence between developed and less developed European countries for the 1977 1990 period. Their results show that labor cost differences are not only large but grew between 1980 and 1986. Flanagen (1993) showed neither convergence nor divergence but rather a substantial wage rate differential. Tovias (1982) tested wage convergence across the European Economic Community (EEC) and found that labor costs converged before the formation of the EEC, continued in that direction for a further 12 years, and then began diverging. Arpaia and Pichelmann (2007) provided a strong indication that asymmetries in labor market adjustments across European countries are substantial and that there are significant differences in both nominal and real wage flexibility. Mokhtari and Rassekh (1989) empirically investigated factor price convergence in the context of trade expansion across 16 OECD countries for the 1961 1984 period. Their results show that trade openness strongly supports factor price convergence.

The empirical literature on wage convergence for European border regions, especially within the context of integration, is scant. Sonja and Ogorevc (2010) analyzed the process of labor cost convergence among European regions using a spatial approach for the 1996 2006 period. Their results confirm an absolute convergence within the EU. They also concluded that the gap between low-wage regions and high-wage regions is narrowing. Niebuhr and Stiller (2006) analyzed the impact of integration and labor markets in European border regions with spatial dependence for the 1995 2000 period. They used Gross Domestic Product (GDP) per capita as a proxy for wages. Their findings suggest a low degree of integration in European labor markets with neighboring border regions. They further concluded that reductions in legal and physical barriers are insufficient to foster integration of labor markets since social and cultural barriers are still playing a role and impeding the process of integration. 
Naveed and Ahmad (2016b) simultaneously considered the effect of structural changes vis-à-vis labor productivity convergence and its speed at the national, regional, and industrial levels. The findings suggest that conditional convergence exists but the speed of convergence is different across different aggregation levels. However, their analysis did not include the effect of international borders.

Hansen et al.'s (2000) case study on the border region between Denmark and Germany concluded that labor markets on both sides of the border remain separated to a large extent. Even though free movement of labor is formally established, this has a very small effect on wages and unemployment levels in labor markets on both sides of the border. The present study is different from the previously discussed literature because none of those studies focused on wages across the European border regions within a panel context. Although Niebuhr and Stiller (2006) attempted to explore the role of integration in border regions, their data is restricted to a short period consisting of only five years; further, they used GDP per capita as a proxy variable to define wages, whereas the current study uses average wages. In their analysis, average is defined in terms of the compensation of employees that is more real and direct, compared with per capita income. In this study, we differentiate between internal and border regions and then examine the process of wage convergence in both types of regions. ${ }^{4}$

\section{Convergence: Concepts and Methods}

\section{A. Conventional approach}

The literature on economic growth proposes multiple methods to capture convergence. ${ }^{5}$ This study will use the concept of $\beta$ convergence. In general, $\beta$ convergence reflects a negative association between the growth rates of a variable and the initial values of that particular variable. Wage convergence is actually a part of real or total convergence. In the context of regional wages, $\beta$ convergence is said to exist if growth rates of wages are

\footnotetext{
${ }^{4}$ Internal and border regions were also used by Naveed and Ahmad (2016a).

${ }^{5}$ There is also a concept of $\sigma$ convergence, but for our study, we use $\beta$ convergence, which is commonly adopted by researchers to investigate convergence. Further, it is not a focus of this study to employ all available types of convergence. See for example Islam (2003) for review of different types of methodologies.
} 
negatively correlated with the initial values of wage rates for each region. In other words, a region with smaller initial values of factor prices has a higher rate of growth than a region with higher initial values of factor prices. Therefore, lower-wage regions grow faster than higher-wage regions. Thus, in the long run, all labor markets tend to converge toward the same average wage. This convergence can be conditional or unconditional.

Unconditional convergence is also an outcome of Solow's (1956) growth model. In that model, unconditional or absolute convergence can be seen when economies are converging toward a single steady state irrespective of their initial endowments of different factors, e.g., population, growth rates, saving rates, labor, capital, and infrastructure. Further, it explains that differences in endowments have a short-run effect but no long-run effects, which means that in the long run, these differences reduce and all economies will move toward the same steady state. Further, conditional convergence is defined when the growth rates depend not only on the initial values of some specific variable but also on the initial endowments of different factors as mentioned above. Conditional convergence can also be detected by considering panel data block growth models with fixed effects. In this case, every economy moves toward its own steady state. Barro and Sala-i-Martin (1991) presented evidence of unconditional income convergence across states as well as conditional convergence by adding regional and sectoral dummies. Mankiw et al. (1992) also provided evidence for both conditional and unconditional income convergence by introducing saving, population growth, and human capital accumulation variables.

The conventional approach for $\beta$ convergence uses a panel version of the growth regression given by Barro and Sala-i Martin (1995). ${ }^{6}$ The basic idea behind this type of regression is to estimate a growth equation with a null hypothesis of divergence against the alternative of convergence. The growth regression for a panel of $\mathrm{n}$ economies and $T$ time periods can be written as

$$
\frac{y_{n, T}-y_{n, 0}}{T}=\alpha+\beta y_{n, 0}+\gamma x_{n}+u_{n}
$$

where the left-hand side of the equation presents average growth rate of variable $y$ and the right-hand side represents the initial lag values of $y \cdot y$ can be any economic variable such as income, wages, or employment. $\alpha$ is a constant, and $u_{n}$ is an error term with zero mean and constant variance. $\gamma$ is the parameter vector revealing the permanent

\footnotetext{
${ }^{6}$ For further details, see Islam (1998).
} 
differences across economies. Thus, after controlling differences across economies $x_{n}$, a negative value of $\beta$ depicts that lower initial values of $y$ are associated with higher growth rates. Therefore, if $\beta<0$, there is convergence, meaning that the differential of variable $y$ diminishes over time. In contrast, if $\beta \geq 0$, it means that the differential of variable $y$ either persists or grows over time. The convergence is classified as unconditional if $\gamma=0$ and conditional otherwise.

The conventional regression approach is not without criticism. Evans and Karras (1996) revealed that even if we control for $90 \%$ of the income variation in a steady state per capita, invalid estimates can still prevail. Levine and Renelt (1992) showed that cross-sectional regressions are not robust to the set of control variables. Evans (1998) suggested that the conventional approach also does not consider cross-sectional heterogeneity, so one cannot establish legitimate output dynamics. Daurlauf and Jhonson (1992) also noted that the conventional approach is unlikely to yield substantial inferences unless it applies to a set of homogenous economies. Further, they empirically established that the performance of the conventional approach with a large sample of heterogeneous economies is very poor. ${ }^{7}$ The conventional approach does not seem to be an appropriate method for the present study as it is an attempt to test the convergence hypothesis for EU border regions, which is a heterogeneous group of regions. On the other hand, the panel unit root test approach utilizes sophisticated econometric techniques that address most of the issues arising from the conventional approach. Therefore, the current study only uses the conventional approach for the graphical understanding of the convergence phenomenon.

\section{B. Convergence in a stochastic world}

To explicate convergence in stochastic terms, the statistical model needs to be described. Following Evans and Karras (1996), suppose that the world consists of $n=$ $1,2,3, \ldots, N$ economies with equal access to the same technology. The non-stochastic neoclassical growth model suggests that there exists a unique path for balanced growth irrespective of countries' initial endowments of different factors, e.g., population, growth rates, saving rate, labor, capital, and infrastructure. Differences in endowments have short-run effects, but no long-run effects, which means that in the long run, these

${ }^{7}$ For a detailed discussion on the invalidity of the conventional approach, see Evans and Karras (1996). 
differences will be reduced and all economies will move toward the same steady state. The balanced growth paths for $N$ economies are also invoked through the assumption of common technology. The state variables only differ by constant amounts. The economies are said to diverge if the deviations from steady state are permanent. In that situation, initial values have a permanent effect rather a temporary effect on long-run growth rates. Evans and Karras (1996) described the balanced growth path mechanism for each economy as follows:

$$
\lim _{i \rightarrow \infty}\left(y_{n, t+i}-a_{t+i}\right)=\mu_{n}
$$

Here, $y_{n, T}$ is the natural logarithm of output. $a_{t}$ is the common trend for economies, and $\mu_{n}$ is the value of the parameter that determines the parallel balanced growth path. $\mu_{n}$ should be non-zero unless all the economies have identical structures. The economies are said to diverge if the deviations from the steady state are permanent, indicating that initial values affect levels in the long run. In contrast, in a stochastic world, convergence is a situation wherein a common trend $a_{t}$ and parameter $\mu_{n}$ exist, such that

$$
\lim _{i \rightarrow \infty} E_{t}\left(y_{n, t+i}-a_{t+i}\right)=\mu_{n}
$$

Unfortunately $a_{t}$ is unobservable, but an estimator of its value can be obtained. Averaging all variables over the $N$ economies, we have

$$
\lim _{i \rightarrow \infty} E_{t}\left(\bar{y}_{t+i}-a_{t+i}\right)=\frac{1}{N} \sum_{n=1}^{N} \mu_{n}
$$

Here, $\bar{y}_{t}=\sum_{n=1}^{N} \frac{y_{n, t}}{N}$. After some manipulation, Evans and Karras (1996) obtained the following condition for convergence:

$$
\lim _{i \rightarrow \infty} E_{t}\left(y_{n t+i}-\bar{y}_{t+i}\right)=\mu_{n} .
$$

The deviations of $y_{1, t+i}, y_{2, t+i}, \ldots, y_{N, t+i}$ from their cross-economy average $\bar{y}_{t}$ can be expected conditional on current information to approach constant values as they tend to infinity. The above equation explains that all economies converge if and only if $y_{n t}$ is non-stationary, but every $y_{n t}-\bar{y}_{t}$ is stationary. Operationally, testing panel unit roots in the panel and testing convergence in a panel are equivalent. If there is unit root in the data, it indicates the absence of convergence or presence of divergence. 


\section{Panel Unit Root Test of Convergence}

Recently, panel unit root methods have been widely applied to test the presence of convergence. These tests examine convergence in stochastic terms and exploit the time series properties of the data (Bernard and Durlauf, 1995). Indeed, such tests are actually an extension of time series unit root tests of stationarity. Stationarity for a panel of regions is a state wherein average values of series of regions are not changing over time. Therefore, the distribution does not depend on the time or cross-sections such as countries and regions. In the current analysis, we prefer these tests instead of conventional methods to analyze convergence. The motivation behind this preference is the higher power and size of these tests relative to other tests of time series stationarity, such as that of Dickey and Fuller (1979) test of unit root, which is used to test if the data generating a process of a time series are stationary or non-stationary. Moreover, the size and power of these tests are enhanced in panel data contexts that consider both the crosssectional and time dimensions. Following Bernard and Durlauf (1995), the stochastic convergence for average wages in region $i, W_{i t}$, and average wages for region $j, W_{j t}$ exists if and only if their difference $\left(W_{i t}-W_{j t}\right)$ is stationary with mean zero. ${ }^{8}$

This approach tests convergence in terms of a unit root null versus the alternative hypothesis of convergence. The panel unit root approach is an easy, advanced, and elegant approach in accessing convergence (Maddala and Wu 1999, Im et al. 2003). To analyze convergence, two parametric panel unit root tests are applied as proposed by Levin et al. (2002) and Im et al. (2003). In addition, as a robustness check of these results, we further apply a non-parametric panel unit root test proposed by Maddala and $\mathrm{Wu}$ (1999) for wage convergence. These texts are discussed below.

\section{A . The Levin-Lin-Chu (2002) test (LLC)}

Levin et al. (2002) developed one of the first panel unit root tests that also incorporates individual effects. They assumed a homogeneous structure for the lagged dependent variable for all the series in the panel. They also assumed that both Time $T$

\footnotetext{
${ }^{8}$ A stationary differential is one that reduces among different regions with the progression of time. Therefore, the values of differentials for wages are greater in earlier years compared with the differentials in later years.
} 
and cross-sections $N$ tend to infinity but $T$ increases at a more rapid rate than $N$ so that $N / T=0$. The structural equation associated with this panel unit root test with individual effects and homogeneous structure of convergence parameter is defined as

$$
\Delta y_{i, t}=\alpha_{i}+\rho y_{i, t-1}+\sum_{k=1}^{K} \phi_{i, k} \Delta y_{i, t-k}+u_{i, t} .
$$

Here, $\alpha_{i}$ are the individual specific effects and $u_{i, t}$ are assumed to follow a stationary process or, in other words, $u_{i, t} \approx i . i . d\left(0, \sigma_{u i}^{2}\right)$, where $i=1,2,3, \ldots, N$, and $t=1,2,3, \ldots, T$.

The homogeneity assumption of the lagged dependent parameter implies that $\rho_{i}=\rho$ for all individual series, which means that all series are converging at the same rate, which implies that wages for all the regions or countries are converging at the same rate if they do converge. Here, the test of convergence is formulated as

$$
H_{0}: \rho_{i}=0, \text { for } \forall i
$$

This null of a unit root is tested against the alternative hypothesis with an auxiliary assumption of $\alpha_{i}=0$ as follows:

$$
H_{1}: \rho_{i}=\rho<0, \text { for } \forall i
$$

This test is based on the adjusted $t^{*}$, which can be calculated as follows:

$$
t_{\rho}^{*}=\frac{t_{\rho}}{\sigma_{T}^{*}}-\operatorname{NTS}\left(\frac{\sigma_{\rho}^{\wedge}}{\sigma_{\varepsilon}^{\wedge 2}}\right)\left(\frac{\mu_{T}^{*}}{\sigma_{T}^{*}}\right) .
$$

Here, $t_{\rho}$ is the $t$-statistic for the pooled value of $\rho . \mu_{T}^{*}$ and $\sigma_{T}^{*}$ are adjusted mean and long-run and short-run standard deviation, respectively, and simulated for various sample sizes. Adjusted $t^{*}$ depends not only on the sample size but also on the ratio of the longrun and short-run variance. Under the non-convergence null hypothesis, $t_{\rho}^{*}$ converges to the normal distribution.

\section{B. The Im-Pesaran-Shin (2003) test (IPS)}

Maddala and Wu (1999) criticized the panel unit root test presented by Levin et 
al. (2002). They argued that the unit root null is valid for testing convergence for all countries, but the alternative that restricts every region to converge with the same rate seems unrealistic. Im et al. (2003) developed a unit root test that allows for individual effects and common time effects. Instead of pooling, Im et al.'s (2003) test is based on the mean of the individual Dickey-Fuller $t$-statistics for each unit in the panel.

The structural equation is as per Levin et al.'s (2002) findings; the difference between the two lies in terms of hypothesis construction. The null hypothesis is the same in both panel unit root tests, which state that all economies have a unit root or diverging from their balancing path:

$$
H_{0}: \rho_{i}=0, \forall i
$$

However, here, the alternative hypothesis allows for a heterogeneous rate of convergence for different economies in the observed sample by assuming a unit root for some but not all economies. Thus, the alternative hypothesis can be written as

$$
H_{1}: \rho_{i} \leq 0
$$

or, more explicitly, as

$$
\begin{gathered}
H_{1}: \rho_{i}<0, \forall i=1,2,3, \ldots, N_{1} \text { and } \\
\rho_{i}=0, \forall i=N_{1}+1, N_{1}+2, \ldots, N
\end{gathered}
$$

This heterogeneous alternative hypothesis allows $\rho$ to vary cross-sectionally compared with the restrictive homogeneity imposed by Levin et al. (2002). This test assumes that a fraction of individual processes $N_{1}$ is stationary with non-zero $\rho$ and tends to a fixed value. Here, $N_{1} / N$, i.e., a fraction of the panels is stationary, with non-zero $\rho$, and tends to a fixed value $\delta$ such that $0<\delta \leq 1$ as $N \rightarrow \infty$. This condition is essential for the consistency of the panel unit root test. Im et al. (2003) computed separate unit root tests for each cross-section and then computed $\bar{t}$ as a simple average of the individual augmented Dickey-Fuller statistics, $t_{i, T}$, as follows:

$$
\bar{t}=\frac{1}{N} \sum_{i=1}^{N} t_{i}
$$


Im et al. (2003) assumed that $t_{i, T}$ has finite mean and variance and independently and identically distributed errors. Therefore, under the null hypothesis, $\bar{t}_{N, T}$ statistics tend to converge to a normal distribution as $N \rightarrow \infty$, following the central limit theorem, i.e.,

$$
\sqrt{N}\left(\frac{\bar{t}_{N, T-\mu}}{\sigma}\right) \Rightarrow N(0,1) \text {. }
$$

This test also assumes that $T$ or the time period is the same for all cross-sectional units; therefore, the mean and variance of $t_{i, T}$ are also the same for all cross-sections. Therefore, Im et al. (2003) panel unit root test is appropriate for balanced panels.

\section{The Maddala-Wu (1999) test (MW)}

Maddala and $\mathrm{Wu}(1999)$ suggested using the Fisher $P(\psi)$ test, which is based on combining the $p$-values obtained by test statistics from the results of individual unit root tests for each cross-section as follows:

$$
P(\psi)=-2 \sum_{i=1}^{N} \ln p_{i}
$$

Here, $P(\psi)$ is the test statistic and $p_{i}$ is the $p$-value from the individual unit root test for the $i^{\text {th }}$ cross-section. Under the null hypothesis of a unit root, $P(\psi)$ is distributed as $\chi^{2}$ with $2 N$ degrees of freedom. Maddala and Wu (1999) showed that the Fisher and Im et al. (2003) tests have more power than the Levin et al. (2002) test as both relax the restrictive assumption of the LLC test concerning strict homogeneity of the autoregressive parameter $\rho$ for all regions. The Im et al. (2003) and Fisher tests both combine information based on the results of individual unit root tests. One of the disadvantages of this test is that it derives the $p$-values for each $t$-statistic through Monte-Carlo simulation. Thus, researchers prefer the Im et al. (2003) test (2003) over the Maddala and Wu (1999) test. Further, this test does not require a balanced panel and thus allows for different time structures across cross-sections. 


\section{Data}

This study covers 203 EU NUTS-2 regions. To analyze wage convergence, data covering a long period are required because convergence is a long-term phenomenon. Because of data restrictions, the direct measure of wages is not available for a longer period for some EU regions. Fortunately, data on labor compensation, which is considered as a good proxy for wages, is available for a reasonably long time period. According to the Eurostat definition, "Compensation of employees (at current prices) is defined as the total remuneration, in cash or in kind, payable by an employer to an employee in return for work done by the latter during the accounting period. Compensation of employees consists of wages and salaries and of employers' social contributions." ${ }^{9}$ For the present analysis, average wage per employee is used, which is a ratio of average compensation to the number of employees in the region. ${ }^{10}$ This study uses this proxy because it covers most labor costs and is superior to per capita income. Data on compensation and total employment were derived from EUROSTAT database 2010. To analyze the convergence process for border regions, the study uses three typologies for regions: first, all regions; second, border regions; and third, internal regions. Together, this can account for all 203 of the sample regions. Border regions include regions with a common international boundary, whereas internal regions are defined as those regions which do not have international borders. Border regions and internal regions are subsamples of all region categories. On the basis of these definitions, the current study defines 83 border regions and 120 internal regions out of the total 203 regions. Borders regions are confirmed using EUROSTAT (2010). ${ }^{11}$

\section{A. Descriptive analysis}

To develop a better understanding of the data, this section provides appropriate descriptive statistics graphical representations. Table 1 provides summary statistics of

\footnotetext{
${ }^{9}$ Data are compiled according to the statistical classification of economic activities in the European Community and values are seasonally adjusted (SA).

${ }^{10}$ Webber and White $(2003,778)$ also used the same definition but call it "average labor price."

${ }^{11}$ Data on compensation of employees are derived from EUROSTAT: http://epp.eurostat.ec.europa.eu/portal/page/portal/statistics/ search_database?_piref458_1209540_458_211810_211810.node_code=nama_r_e2rem. Data on employment are taken from: http://appsso. eurostat.ec.europa.eu/nui/show.do?dataset=lfst_r_lfe2emp\&lang=en.
} 
the data used for the analysis. The mean for all three types of regions ranges in between 23 and 26. The dispersion of wages relative to the mean is marginally higher for border regions compared with that for all European regions and internal regions.

Table 1. Descriptive statistics of regional data

\begin{tabular}{|l|c|c|c|c|c|}
\hline \multicolumn{1}{|c|}{ Variable } & Observation & Mean & $\begin{array}{c}\text { Standard } \\
\text { deviation }\end{array}$ & Minimum & Maximum \\
\hline Year & 2233 & 2001 & 3.16 & 1996 & 2006 \\
\hline Regions & 2233 & 126.19 & 88.14 & 1 & 203 \\
\hline Compensation & 2233 & 20732.74 & 23593.96 & 284.8 & 271315 \\
\hline Employment & 2233 & 823.94 & 693.18 & 15.1 & 5495.1 \\
\hline Wages: All EU Regions & 2233 & 23.84 & 9.40 & 0.56 & 104.94 \\
\hline Wages: Border EU Regions & 913 & 20.70 & 10.24 & 0.56 & 39.30 \\
\hline Wages: Internal EU Regions & 1320 & 26.00 & 8.10 & 3.58 & 104.94 \\
\hline
\end{tabular}

(Note) Compensation is measured in millions of Euros (from 1999/01/01)/millions of the European Currency Unit (up to 1998/12/31) and employment is measured in thousand-persons, EU : European Union.

Higher dispersion might be a tentative sign of divergence or a low level of convergence. The total number of observations is equal to the product of regions and time periods, which is 2,233 .

\section{B. Graphical analysis}

This section analyzes the data in two different ways. First, it presents the average trend of wages over the period of analysis. Second, this section also graphically presents the wage convergence pattern for all categories of regions by utilizing the conventional $\beta$ convergence approach. Figure 1 illustrates a growing trend of average wages for European internal and European border regions. 


\section{Figure 1. Wage trends for European internal and border regions}

(EU NUTS-2 regions)

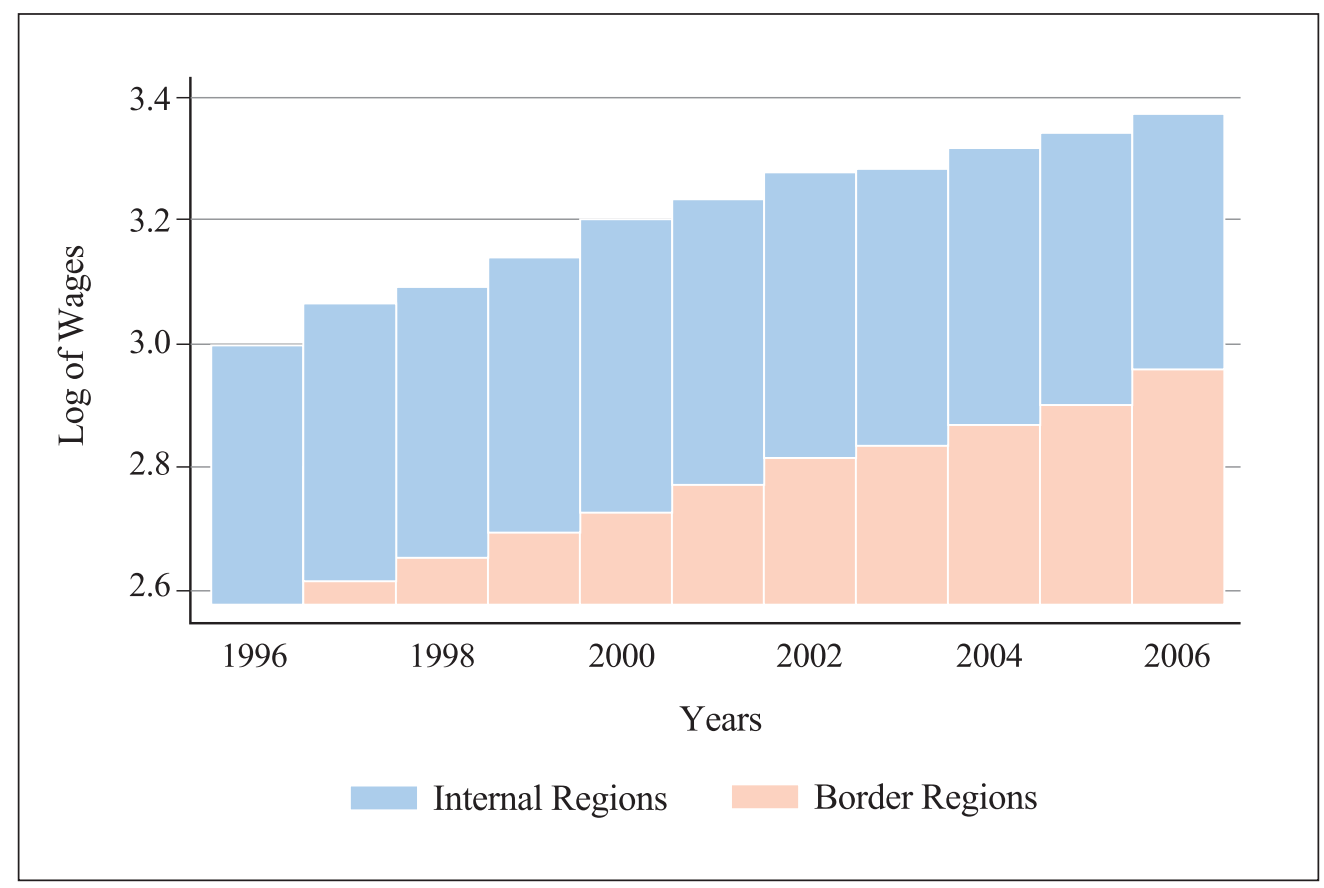

(Note) EU: European Union, NUTS: Nomenclature of Territorial Units for Statistics. Log of wages data on the vertical axis. Horizontal axis reports the corresponding years. Wages are measured in millions of Euros.

(Source) Author's calculation.

The time-averages of wages for all internal regions and all border regions are illustrated in Figure 1. There is an upward trend for both internal and border regions through the period of analysis (1996 2006).

This upward trend for average wages is larger for internal regions but smaller for border regions. Thus, there are significant disparities among the average wage trend for both types of regions. Convergence patterns for average wages for all categories are shown in Figure 2, wherein we attempt to analyze wage convergence by utilizing the concept of $\beta$ convergence, which is based on a negative association between growth rates of a factor and its initial values. 
Figure 2. Wage convergence pattern in all European Union regions

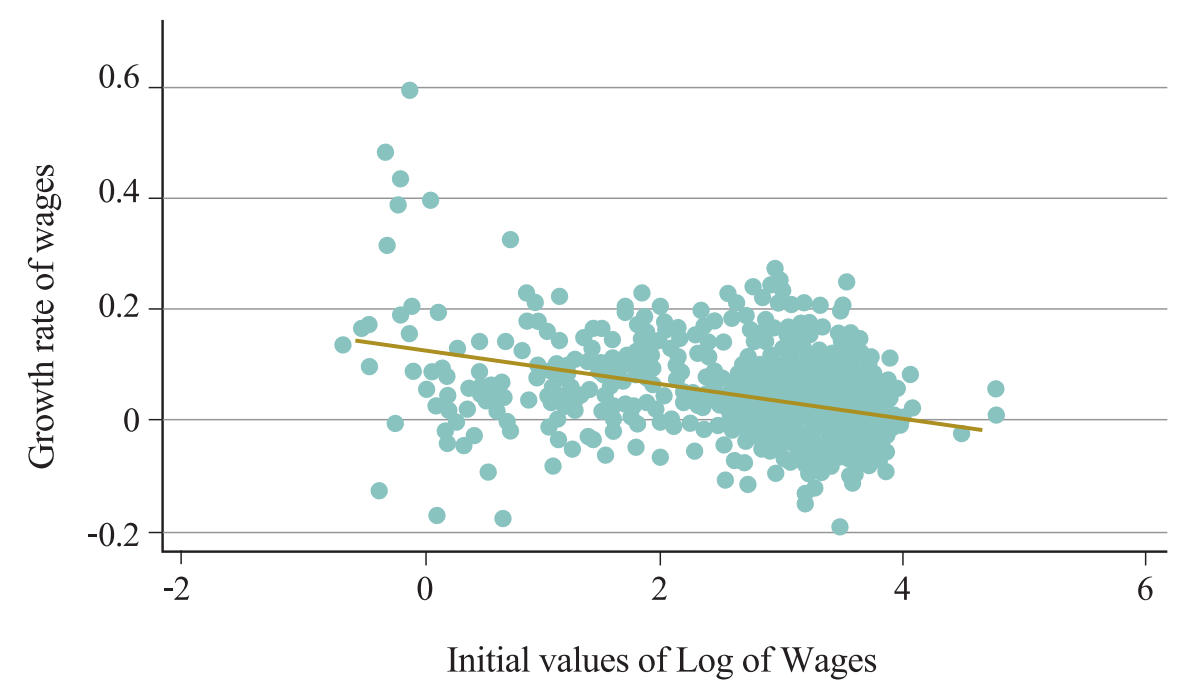

- Growth rate of wages — Fitted values

(Note) Fitted values are obtained using ordinary least square method. Initial values of wages in log form are measured on $\mathrm{x}$-axis and growth rate of wages are measured on $\mathrm{y}$-axis. Wages are measured in millions of Euros.

(Source) Author's calculation.

Figure 2, Figure 3, and Figure 4 present scatter plots for growth rates of wages and initial values. Figure 2 shows the convergence pattern for all 203 European regions. A clear inverse relation between growth rates of average wages and its initial values is evident. Thus, for most of the regions, convergence in average wages seems to be occurring. It can be stated that regions with lower initial average wages are growing faster than the regions with higher initial wages. In spite of these converging regions, there are some outliers that deviate from the common path of convergence. To explore these outliers further, we split the convergence pattern graph into internal and border regions since the entire European regions category is a combination of internal regions and border regions.

Figure 3 and Figure 4 illustrate the convergence patterns for internal and border categories. It is obvious from these figures that convergence in average wages is stronger for the internal regions than border regions. Further, the outlying regions are found to exist in the border region category. Although many border regions appear to be catching 
up, some of them show either a divergent path or a positive relation between growth rates and their initial average wages. This means that initial average wages for these outliers are higher (lower), but the growth rates are also higher (lower) throughout the period of analysis. Thus, the convergence hypothesis does not seem to hold for these outliers, which include the Danish-German border region, the Belgian border with the Netherlands, and the French border with Germany. Therefore, as a first result based on the graphical presentation of the data, average wages are not converging within these border regions. Through graphical analysis, it can be roughly concluded that the convergence hypothesis hold for internal and all European regions, but for border regions, the evidence seems to be equivocal.

Figure 3. Wage convergence pattern in the $\mathbf{E U}$ border regions

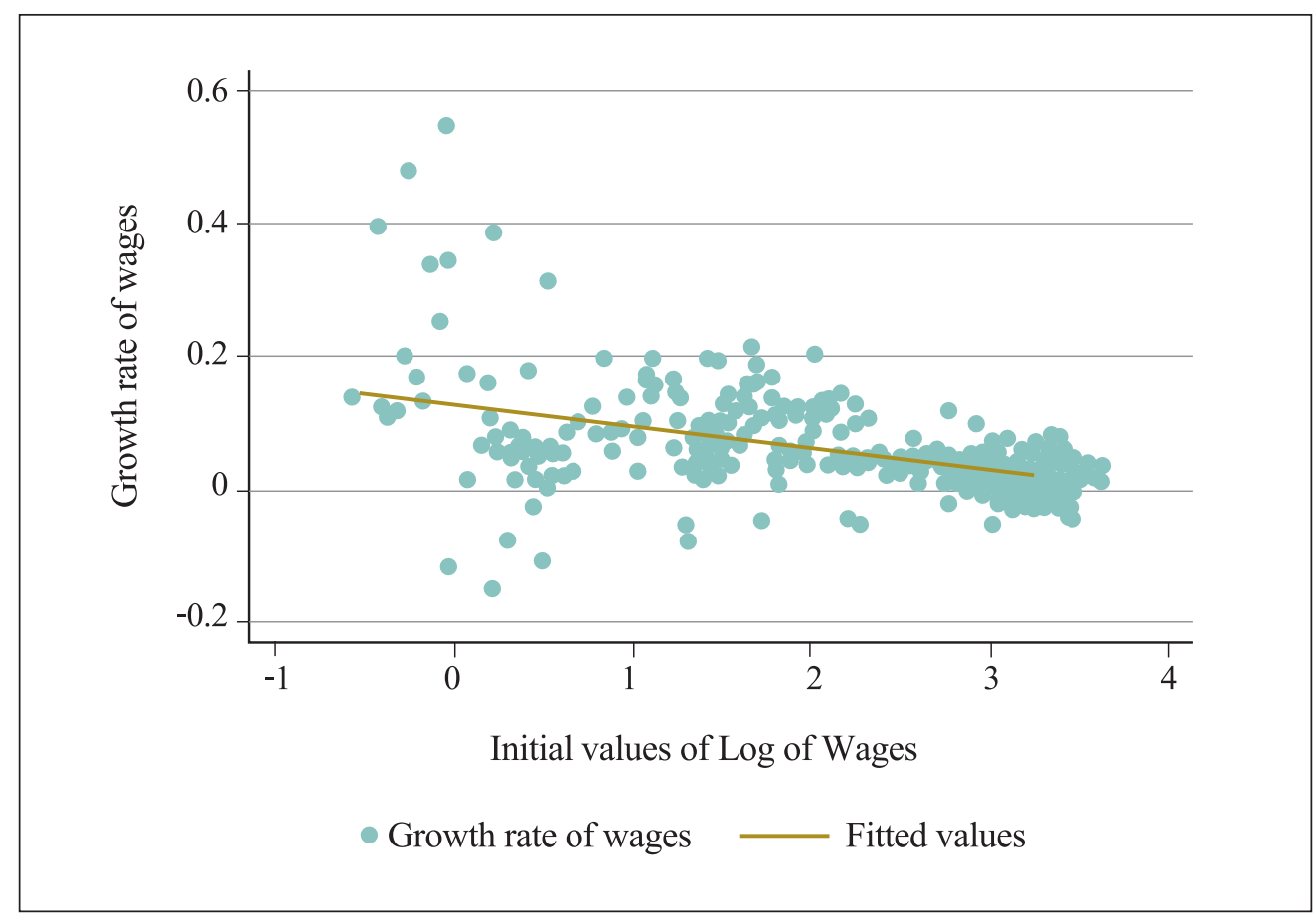

(Note) Fitted values are obtained using ordinary least square method. Initial values of wages in log form are measured on $\mathrm{x}$-axis and growth rate of wages are measured on $\mathrm{y}$-axis. Wages are measured in millions of Euros.

(Source) Author's calculation. 
Figure 4. Wage convergence pattern in the $\mathrm{EU}$ internal regions

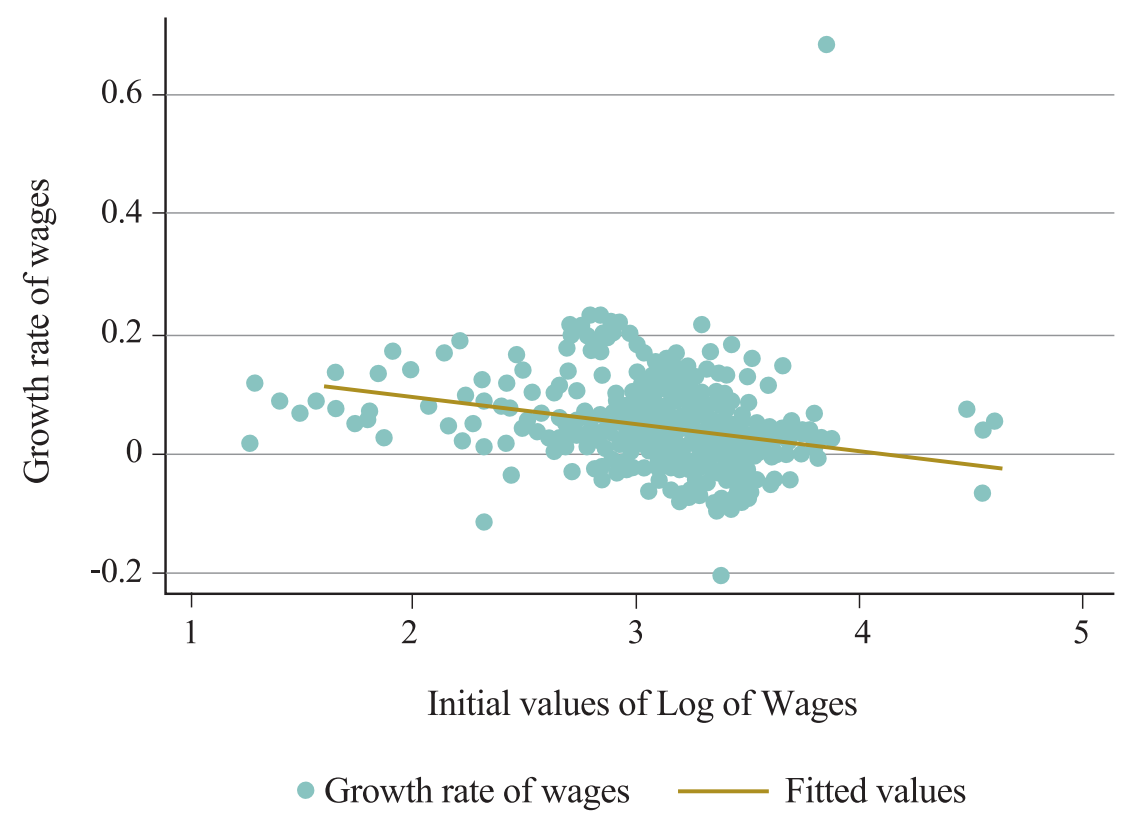

(Note) Fitted values are obtained using ordinary least square method. Initial values of wages in log form are measured on $\mathrm{x}$-axis and growth rate of wages are measured on $\mathrm{y}$-axis. Wages are measured in millions of Euros.

(Source) Author's calculation.

\section{Empirical Results}

This section provides the estimated results for average wage convergence by applying the panel unit root tests described in Section IV. The current study utilizes both parametric and non-parametric tests to analyze average wage convergence. Parametric tests include the LLC and IPS panel unit root tests, whereas the non-parametric test includes the MW panel unit root test, which is based on $p$-values, is also employed. For both LLC and IPS panel unit root tests, the current study has used two lags to test serial correlation among the errors to avoid potential correlation bias for the estimated parameters. The null hypothesis for all the three tests consists of a unit root (or no 
convergence) for each analyzed region. The alternative hypothesis for the LLC test is different from IPS and MW tests because it imposes a homogenous structure on the parameter of the lagged variable, which is defined here as lagged values of average wages. Given the context of average regional wages, the homogeneous parameter delimits a state wherein all average regional wages are converging at the same rate or with the same intensity. The results of the LLC panel unit root test are given in Table 2. The results are reported for three different specifications of Equation 6. The first specification reports results without individual specific effects, presented as $L L C_{1}$; the second specification reports the results with individual specific effects, $L L C_{2}$; and the last specification accounts for both individual specific effects and cross-sectional dependence, $L L C_{3}$. Cross-sectional dependence is addressed by demeaning the regions to mitigate the effect of regional dependence.

Table 2 reports the results for border regions, internal regions, and all 203 regions. Results for $L L C_{1}$ provide evidence of unit roots for all three categories of regions and thus suggest that average wages in European regions are not converging. In other words, there is no catching up with regard to average wages in European regions. For $L L C_{1}$, it is assumed that average wages are not conditional on the individual characteristics of the respective region and these characteristics can be the flexibility of labor markets, the effectiveness of labor unions, the mobility of workers, etc. Therefore, an auxiliary result derived from these results is the absence of unconditional (or absolute) convergence for all three categories of regions; this is evident from the $p$-values reported in the parentheses. $L L C_{2}$ confirms average wage convergence for internal and all regions but provides no evidence of wage convergence for the border regions. Further, geographical heterogeneity among the regions based on borders does matter for convergence analysis. We see diverse results for different typologies of regions. There is evidence of convergence for all 203 European regions and internal regions but no evidence for border regions. Consequently, it can be said that the distinction of regions on the basis of borders really does matter for determining average wage convergence. Further, there is wage convergence for internal regions and all regions, but it is conditional on the individual characteristics of regions, which means that each region is converging to its own steady state rather than converging to the same steady state. ${ }^{12}$ For all categories of regions, the same results are obtained like $L L C_{2}$ after controlling for region specific characteristics and regional dependence. For $L L C_{3}$, average wages in border regions still

\footnotetext{
${ }^{12}$ A steady state for an economy is defined as a state wherein all the economic variables are working at their optimal or full employment level.
} 
show no convergence even after controlling for fixed regional effects and cross-sectional dependence. The test statistics for $L L C_{2}$ and $L L C_{3}$ are highly significant for internal regions even at the one-percent level of significance.

\section{Table 2. Results for wage convergence}

(Based on the methodology by Levin, Lin, and Chu (2002))

\begin{tabular}{|l|c|c|c|}
\hline \multicolumn{1}{|c|}{ Regions } & All & Border & Internal \\
\hline$L L C_{1}$ & $\begin{array}{c}21.43 \\
(1.000)\end{array}$ & $\begin{array}{c}13.41 \\
(1.000)\end{array}$ & $\begin{array}{c}17.00 \\
(1.000)\end{array}$ \\
\hline$L L C_{2}$ & $\begin{array}{c}-6.34 * * * \\
(0.000)\end{array}$ & $\begin{array}{c}2.58 \\
(0.995)\end{array}$ & $\begin{array}{c}-10.36^{* * *} \\
(0.000)\end{array}$ \\
\hline$L L C_{3}$ & $-15.48^{* * *}$ & 0.757 & $-9.68^{* * *}$ \\
& $(0.000)$ & $(0.775)$ & $(0.000)$ \\
\hline Lags(ADF) AIC & 2 & 2 & 2 \\
\hline Bartlett kernel, lags & 7 & 7 & 7 \\
\hline Number of regions & 203 & 83 & 120 \\
\hline $\mathrm{N}$ & 2233 & 913 & 1320 \\
\hline
\end{tabular}

(Note) (i) LLC:Levin-Lin-Chu test, AIC = Akaike information criterion; ADF = Augmented Dickey-Fuller test

(ii) $p$-values are reported in parentheses. $(*)$ significant at the $10 \%$ level, $(* *)$ significant at the $5 \%$ level, (***) significant at the $1 \%$ level.

(iii) Panel means are included in all specifications. To estimate long-run variance, the LLC panel unit root test chooses the Bartlett kernel criterion.

The results from the LLC tests imply that internal regions and all regions are getting closer with respect to their wages since LLC tests assume a homogeneous structure for the parameter of the lagged dependent variable. Under the null hypothesis, the test statistics follow a standard normal distribution as $N$ and $T \rightarrow \infty$. ${ }^{13}$

Table 3 presents IPS panel unit root test results for all three categories of regions. Equation (6) is estimated by considering two important aspects; first the regional individual effects, and second the cross-sectional dependencies. Addressing the first issue by including regional characteristics and results are reported as IPS . IPS reports the results both with region specific effects and cross-sectional dependence. Results for $I P S_{1}$

\footnotetext{
${ }^{13}$ In Table 2, $L L C_{1}$ is the panel unit root test without individual characteristics, $L L C_{2}$ is a test with individual effects, and $L L C_{3}$ is the test with both individual effects and demeaning option to reduce the cross regional effect. For all three tests, we take two lags for prewhitening of the data.
} 
strongly reject the convergence hypothesis for both internal and border regions, whereas results for $I P S_{2}$ suggest that the convergence hypothesis holds for internal regions but not for border regions. These results suggest that both individual effects and cross regional dependencies are playing an important role in identifying wage convergence. Therefore, cross regional dependence could be one of the issues that should be addressed while analyzing convergence.

As far as the border regions are concerned, no evidence of convergence for border regions has been found. The null hypothesis of a unit root for border regions is strongly accepted as it is indicated by the $p$-value of both $I P S_{1}$ and $I P S_{2}$ tests. In other words, wages are converging for regions within the country and not showing any convergence for the border regions. These results indicate that labor markets of border regions are still separated even though free trade and mobility have been established. The IPS panel unit root test is more powerful than the LLC test as it allows a heterogeneous structure for the autoregressive parameter for different regions under the alternative hypothesis; this seems to be more realistic in this context because different regions, especially the border regions, could be at different levels of development and are characterized by different labor market structures. Therefore, it seems to be more realistic to consider a different rate of convergence for different regions.

\section{Table 3. Results for wage convergence}

(Based on the methodology by Im, Pesaran, and Shin (2003))

\begin{tabular}{|l|c|c|c|}
\hline \multicolumn{1}{|c|}{ Regions } & All & Border & Internal \\
\hline \multirow{2}{*}{$I P S_{1}$} & 5.62 & 7.25 & 1.27 \\
& $(1.000)$ & $(1.000)$ & $(0.993)$ \\
\hline \multirow{2}{*}{$I P S_{2}$} & $-3.13 * * *$ & 5.73 & $-4.61^{* * *}$ \\
& $(0.001)$ & $(1.000)$ & $(0.000)$ \\
\hline Lags(ADF) AIC & 2 & 2 & 2 \\
\hline Number of Regions & 203 & 83 & 120 \\
\hline $\mathrm{N}$ & 2233 & 913 & 1320 \\
\hline
\end{tabular}

(Note) (i) IPS = Im-Pesaran-Shin test; AIC = Akaike information criterion; ADF = Augmented DickeyFuller test.

(ii) $p$-values are reported in parentheses. $(*)$ significant at the $10 \%$ level, $(* *)$ significant at the $5 \%$ level, $(* * *)$ significant at the $1 \%$ level.

(iii) Panel means are included in all specifications. To estimate long-run variance, the LLC panel unit root test chooses the Bartlett kernel criterion. Panel means are included in all specifications. 
To explore the robustness of test results, Table 4 reports test results associated with the Maddala and $\mathrm{Wu}$ (1999) panel unit root test. This is a non-parametric panel unit root test, based on the $p$-values obtained from unit root tests for each region. Table 4 reports the results with two different options. $M W_{1}$ is estimated with cross regional means while $M W_{2}$ is estimated without cross regional means to mitigate cross regional dependence from the panel. The results are in line with the results from LLC and IPS tests for all regions and internal regions which confirms the evidence for wage convergence. As far as border regions are concerned the results are different from the previous two test results. Here the convergence hypothesis seems to hold at the $5 \%$ level for $M W_{1}$ and at the $1 \%$ for $M W_{2}$. These results suggest that wages are converging not only for internal regions but also for cross-border regions.

\section{Table 4. Results for wage convergence}

(Based on the methodology by Maddala and Wu (1999))

\begin{tabular}{|l|c|c|c|}
\hline \multicolumn{1}{|c|}{ Regions } & All & Border & Internal \\
\hline$M W_{1}$ & $\begin{array}{c}52.30^{* * *} \\
(0.000)\end{array}$ & $\begin{array}{c}211.29 * \\
(0.010)\end{array}$ & $\begin{array}{c}311.71 * * * \\
(0.001)\end{array}$ \\
\hline$M W_{2}$ & $\begin{array}{c}672.05^{* * *} \\
(0.000)\end{array}$ & $\begin{array}{c}354.45^{* * *} \\
(0.000)\end{array}$ & $\begin{array}{c}404.96 * * * \\
(0.000)\end{array}$ \\
\hline $\mathrm{DF}$ & 406 & 166 & 240 \\
\hline Lags(ADF) AIC & 2 & 2 & 2 \\
\hline Number of Regions & 203 & 83 & 120 \\
\hline $\mathrm{N}$ & 2233 & 913 & 1320 \\
\hline
\end{tabular}

(Note) (i) MW: Maddala -Wu test, AIC: Akaike information criterion, DF: Degree of freedom.

(ii) $p$-values are reported in parentheses. $(*)$ significant at the $10 \%$ level, $(* *)$ significant at the $5 \%$ level, $(* * *)$ significant at the $1 \%$ level.

(iii) Panel means are included in all specifications. To estimate long-run variance, the LLC panel unit root test chooses the Bartlett kernel criterion. Panel means are included in all the specifications.

Thus, results for wage convergence in border regions are not robust to test specification. The results for border wages are sensitive to the analytical techniques. There is a discrepancy in the results for border wages for parametric and non-parametric panel unit root tests. That discrepancy could be explained through the asymptotic properties for both the IPS and MW tests. Maddala and Wu (1999) explained that the asymptotic validity of both IPS and Fisher tests rely on different conditions. The validity 
of asymptotic results for the IPS test relies on the number of cross-sections.

The results for all regions are in line with many other studies with respect to wage convergence for EU regions. For instance, Sonja and Ogorevc (2010) demonstrated the existence of labor cost convergence using data for 210 EU regions. In addition, Webber and White (2003) confirmed factor average wage convergence for $58 \mathrm{EU}$ regions.

For internal regions, convergence seems to be stronger because the labor market conditions are more similar than markets over border regions. As far as wage convergence of border regions is concerned, results are in line with Niebuhr and Stiller (2006), who find that border effects are still hampering regional integration through non-tariff impediments. The labor markets of European regions are still fragmented. However, the results are contrary to the findings of Puga (1999).

In summary, this study provides evidence of wage convergence for all $203 \mathrm{EU}$ regions and 120 internal regions. These results are in line with previous studies (Jung and Doroodian 2000, Webber and White 2003, and Webber 2001). Wage convergence in border regions is still disparate. An adverse border effect is still powerfully resisting the integration process vis-à-vis wages in European border regions. Niebuhr and Stiller (2006) also found that on average, unemployment and per capita income are relatively more different in border regions than in regions within the same country. The results also generalize the results of a case study by Hansen (2000) for the Danish-German border region, which concluded that labor markets on both sides of the border remain largely separated even though free movement of labor has been formally established; this causes a very small effect on wages and the unemployment level in labor markets on both sides on the border.

\section{Conclusion}

This study primarily aimed to consider the role of international borders on wage convergence among EU member states. Specifically, we addressed three important questions in our empirical analysis. First, we attempted to determine if there is any evidence of wage convergence among EU regions. Second, we evaluated whether regional wages are converging to a single, steady state level (unconditional convergence) or each region is converging to their own steady state levels (conditional convergence). 
Finally, we considered the role of international borders in the process of wage convergence. The contribution of this study is two-fold. First, it contributes to the literature on wage convergence for European regions, and second, it will also contribute to the literature on integration among EU border regions.

For estimation purposes, we used a unique data set for 203 NUTS-2 level EU regions over the 1996 2006 period. With regard to econometric specifications, we exploited the advantages of time series and cross-sectional properties by applying panel data modeling techniques for testing convergence hypothesis. This study's results show that wage convergence exists for all regions and internal regions. Furthermore, we found that wage convergence is conditional rather than absolute, which implies that average wages for each region are converging to their own steady state rather than converging to a unique steady state. The reason could be that there is a shift of employment from one sector to another (structural change process), which may explain the nature of conditional wage convergence across different countries and regions as explained by Naveed and Ahmad (2016b). We can infer that regional average wages are much dependent on the local forces of local labor markets such as demand and supply of labor and institutions.

With regard to the effect of international borders, the results are not robust across different specifications. The non-existence of convergence among border regions implies that there a slow process of economic integration is ongoing among EU regions. These findings also suggest that reductions in the legal, physical, and administrative barriers are insufficient to integrate the labor markets with respect to returns to the factors of production. Another explanation might be that there are certain social and economic factors that serve as barriers to the wage convergence process. For instance, language barriers, cultural differences, local rules and regulations, legal issues, and property rights may reduce the process of wage convergence, as explained by Naveed and Ahmad (2016a) in the context of knowledge transfer across the international border. Therefore, for the integration of wages in border regions, these barriers may need to be reduced. Thus, our findings suggest that EU instruments aimed at convergence are working well for internal regions but not enough to narrow the wage gap in border regions. For future research, it would be interesting to incorporate geographical (spatial) aspects to analyze the impact of borders on wage convergence in greater depth.

Received 2 January 2017, Revised 15 January 2017, Accepted 26 January 2017 


\section{References}

Arpaia, Alfonso, and Karl Pichelmann. "Nominal and real wage flexibility in EMU." International Economics and Economic Policy 4, no. 3 (2007): 299-328.

Barro, Robert J., Xavier Sala-i-Martin, Olivier Jean Blanchard, and Robert E. Hall. "Convergence across states and regions." Brookings papers on economic activity (1991): 107-182.

Bauer, Thomas K., and Klaus F. Zimmermann. Assessment of Possible Migration Pressure and its Labour Market Impact Following EU Enlargement to Central and Eastern Europe. (1999).

Bernard, Andrew B., and Steven N. Durlauf. "Convergence in international output." Journal of Applied Econometrics 10, no. 2 (1995): 97-108.

Dickey, David A., and Wayne A. Fuller. "Distribution of the estimators for autoregressive time series with a unit root." Journal of the American statistical association 74, no. 366a (1979): 427-431.

Ericksno, Christopher L., and Sarosh Kuruvilla. "Labor costs and the social dumping debate in the European Union." Industrial \& Labor Relations Review 48, no. 1 (1994): $28-47$.

Evans, Paul, and Georgios Karras. "Convergence revisited," Journal of Monetary Economics 37, no. 2 (1996): 249-265.

Flanagan, Robert J., Karl Ove Moene, and Michael Wallerstein. Trade Union Behaviour, Pay Bargaining and Economic Performance. In FIEF Studies Labour Markets and Economic Policy, Clarendon Press, Oxford, 1993, 165 pp. ISBN 0-19-828798-4. (1996): 321-327.

Hansen, Christian L., and Birgit Nahrstedt. "Cross-Border Commuting: Research Issues, and a Case Study for the Danish-German Border Region." Borders, Regions, and People, European Research in Regional Science 10 (2000).

Im, Kyung So, M. Hashem Pesaran, and Yongcheol Shin. "Testing for unit roots in heterogeneous panels.” Journal of Econometrics 115, no. 1 (2003): 53-74.

Islam, Nazrul. "Growth empirics: a panel data approach." The Quarterly Journal of Economics (1995): 1127-1170. 
Islam, Nazrul. "What have we learnt from the convergence debate?." Journal of Economic Surveys 17, no. 3 (2003): 309-362.

Jung, Chulho, and Khosrow Doroodian. "Labor costs convergence in manufacturing between North America and Western Europe, 1960-1991." Journal of Economic Studies 27, no. 6 (2000): 514-525.

Krugman, Paul R., Maurice Obstfeld, and Marc Melitz, International Economics: Theory and Policy (Prenctice Hall), (2011).

Leamer, E. E, The Heckscher-Ohlin Model in Theory and Practice, No. 77. International Economics Section, Departement of Economics Princeton University, 1995.

Levin, Andrew, Chien-Fu Lin, and Chia-Shang James Chu. "Unit root tests in panel data: asymptotic and finite-sample properties." Journal of Econometrics 108, no. 1 (2002): 1-24.

Levine, Ross and David Renelt, "A Sensitivity Analysis of Cross-Country Growth Regressions," American Economic Review, September 1992, 82 (4), 942-63.

Maddala, Gangadharrao S., and Shaowen Wu. "A comparative study of unit root tests with panel data and a new simple test." Oxford Bulletin of Economics and statistics 61, no. S1 (1999): 631-652.

Mankiw, N. Gregory, David Romer, and David Weil. "A Contribution to the Empirics of Economic Growth." The Quarterly Journal of Economics 107, no. 2(1992): 407-37.

Mokhtari, Manouchehr, and Farhad Rassekh. "The tendency toward factor price equalization among OECD countries." The Review of Economics and Statistics (1989): 636-642.

Mora, Toni, Jordi Lòpez-Tamayo, and Jordi Suriñach. "Are wages and productivity converging simultaneously in Euro-area countries?." Applied Economics 37, no. 17 (2005): 2001-2008.

Naveed, Amjad, and Nisar Ahmad. "Technology spillovers and international borders: a spatial econometric analysis." Journal of borderland Studies 31, no.4 (2016a): 441-461.

Naveed, Amjad, and Nisar Ahmad. "Labour productivity convergence and structural changes: simultaneous analysis at country, regional and industry levels." Journal of Economic Structures 5, no. 1 (2016b): 1-17.

Naveed, Amjad, Nino Javakhishvili Larsen, and Torben Dall Schmidt. "Labour Mobility 
and Local Employment: Building a Local Employment Base from Labour Mobility?." Regional Studies (2016): Accessed December 16, 2016. doi: 10.1080/00343404. 2016.1223284.

Niebuhr, Annekatrin and Silvia Stiller, "Integration and labour markets in European borderregions. Zeitschrift fr ArbeitsmarktForschung." Journal for Labour Market Research 39, no. 1 (2006): 57-76.

Ohlin, Bertil. "1933 and 1977--Some Expansion Policy Problems in Cases of Unbalanced Domestic and International Economic Relations." The American Economic Review 83, no. 6 (1993): 10-17.

Overman, Henry G., and Diego Puga. "Unemployment clusters across Europe's regions and countries." Economic Policy 17, no. 34 (2002): 115-148.

Samuelson, Paul A. "International trade and the equalisation of factor prices." The Economic Journal 58, no. 230 (1948): 163-184.

Šlander, Sonja, and Marko Ogorevc. "Labour Cost Convergence in the EU: Spatial Econometrics Approach.” Privredna Kretanja i Ekonomska Politika 20, no. 122 (2010): 27-52.

Solow, Robert M. "A Contribution to the Theory of Economic Growth.” Quarterly Journal of Economics 70, no. 1 (1956): 65-94.

Revenga, Ana. "Employment and wage effects of trade liberalization: the case of Mexican manufacturing." Journal of Labor Economics 15, no. S3 (1997): S20-S43.

Taylor, Alan M. and Jeffrey G. Williamson. "Convergence in the age of mass migration." European Review of Economic History 1, no. 1 (1997): 27-63.

Tovias, Alfred. "Testing factor price equalization in the EEC." Journal of Common Market Studies 20, no. 4 (1982): 375-388.

Webber, Don, and Paul White. "Regional factor price convergence across four major European countries.” Regional Studies 37, no. 8 (2003): 773-782.

Webber, Don J. "Convergence of labour's factor reward between regions of the EU." Applied Economics Letters 8, no. 5 (2001): 355-357.

EUROSTAT. "European Statistics (EUROSTAT).” http://ec.europa.eu/eurostat/data/ database. Accessed November (2010). 